\title{
ANALISIS CFD UNJUK KERJA SIKLON DENGAN MENGGUNAKAN MODEL TURBULEN SPALART-ALLMARAS DAN RNG k- $\varepsilon$
}

\author{
Suyitno \\ Jurusan Teknik Mesin Fakultas Teknik \\ Universitas Sebelas Maret Surakarta \\ J1. Ir. Sutami 36A Surakarta \\ msuyitno@yahoo.com
}

\begin{abstract}
ABSTRAKSI
Penelitian ini bertujuan untuk menganalisa karakteristik aliran dan unjuk kerja siklon terhadap pengaruh kecepatan gas masuk. Penelitian akan dilakukan secara numerik. Hasil dari analisa CFD (Computational Fluid Dynamic) akan dibandingkan dengan hasil eksperimen dari literatur lain. Karena aliran dalam siklon dipercaya termasuk kedalam jenis turbulen sehingga dalam analisa CFD juga perlu melibatkan pengaruh turbulen dalam pemecahan persamaan momentumnya (Navier Stokes). Dua model turbulen yaitu Spalart-Allmaras dan $R N G$ k-E akan dilibatkan dalam perhitungan numerik. Dari hasil perhitungan numerik dan hasil eksperimen dapat disimpulkan bahwa desain siklon pada penelitian ini masih memungkinkan terjadinya aliran pintas. Besarnya efisiensi pemisahan partikel yang terjadi di atas $90 \%$ dan tidak tergantung secara signifikan pada kecepatan gas masuk. Peningkatan kecepatan gas masuk dari $13,2 \mathrm{~m} / \mathrm{s}$ menjadi $17,8 \mathrm{~m} / \mathrm{s}$ akan meningkatkan penurunan tekanan hampir dua kali lipat. Model Spalart-Allmaras lebih baik dalam memprediksi penurunan tekanan dan efisiensi pemisahan partikel dalam siklon untuk kisaran kecepatan gas masuk $13,2 \mathrm{~m} / \mathrm{s}$ sampai $17,8 \mathrm{~m} / \mathrm{s}$ dibandingkan model turbulen $R N G \mathrm{k}-\mathcal{E}$.
\end{abstract}

Kata-kata kunci: CFD, siklon, penurunan tekanan, efisiensi, turbulen

\section{PENDAHULUAN}

Siklon (cyclone) karena karakteristiknya sering digunakan sebagai alat pemisah partikel dengan gas. Penggunaan siklon sering dijumpai sebagai alat pengontrol polusi udara dari pengotor debu. Siklon juga dijumpai pada proses pembakaran untuk peralatan umpan bahan bakar padat (pulverized) pada boiler. Alasan utama penggunaan siklon adalah harganya yang murah, tidak mempunyai bagian yang bergerak dan mampu bertahan pada kondisi operasi yang berat.

Sementara itu siklon juga mempunyai beberapa kelemahan dalam hal efisiensinya yang rendah (khususnya pada partikel yang sangat kecil) dan biaya operasi yang tinggi. Tingginya biaya operasi dikarenakan siklon perlu daya yang besar untuk mengatasi penurunan tekanan (pressure drop).

Prinsip kerja dari siklon adalah terdapatnya kumpulan partikel dan gas yang masuk dalam arah tangensial ke dalam siklon pada bagian puncaknya. Kumpulan gas dan partikel ditekan ke bawah secara spiral karena bentuk dari siklon. Gaya sentrifugal dan gaya inersia menyebabkan partikel terlempar ke arah luar, membentur dinding dan kemudian 
bergerak turun ke dasar siklon. Dekat dengan bagian dasar siklon, gas bergerak membalik dan bergerak ke atas dalam bentuk spiral yang lebih kecil (lihat Gambar 1). Gas yang bersih keluar dari bagian puncak siklon sedangkan partikel keluar dari dasar siklon.

Siklon sering digambarkan sebagai peralatan dengan efisiensi rendah. Namun dalam perkembangannya, tercatat, siklon mampu menghasilkan efisiensi $98 \%$ bahkan lebih untuk partikel yang lebih besar dari 5 microns (Cooper, et al., 1986). Efisiensi lebih dari $98 \%$ juga tercatat pada siklon untuk partikel yang diameternya lebih dari 346 microns (Funk, P.A., et al., 2000).

\section{TINJAUAN PUSTAKA}

Berbagai usaha penelitian terus dilakukan untuk meningkatkan unjuk kerja dari siklon. Modifikasi pada geometri dan ukuran pada aliran masuk siklon selain akan menyebabkan diperolehnya sedikit peningkatan efisiensi tetapi juga terjadi kenaikan penurunan tekanan.

Penelitian pengaruh perubahan sudut aliran masuk $45^{\circ}$ terhadap badan siklon juga pernah dilakukan. Penelitian dilakukan secara numerik dengan menggunakan RSM (Reynolds Stress Model) sebagai model turbulen. Penelitian ini menunjukkan bahwa akan terjadi peningkatan kecepatan tangensial di dalam siklon tanpa terjadi peningkatan penurunan tekanan dengan mengubah sudut aliran $45^{\circ}$ terhadap badan siklon (Bernardo et al., 2005).

Penelitian pada perubahan diameter badan siklon dan diameter pipa gas keluar diperoleh hasil bahwa perubahan keduanya tidak mempunyai pengaruh secara signifikan pada efisiensi. Penelitian selanjutnya menunjukkan bahwa siklon dengan bukaan kerucut (cone) yang lebih kecil akan mempunyai efisiensi lebih tinggi. Ini menunjukkan bahwa partikel secara nyata dipercepat dalam seksi kerucut akibat pengecilan luasan penampang kerucut secara bertahap. Luas penampang yang lebih kecil akan menghasilkan kecepatan tangensial yang lebih besar dan gaya sentrifugal yang lebih besar terjadi pada partikel di dalam aliran gas.

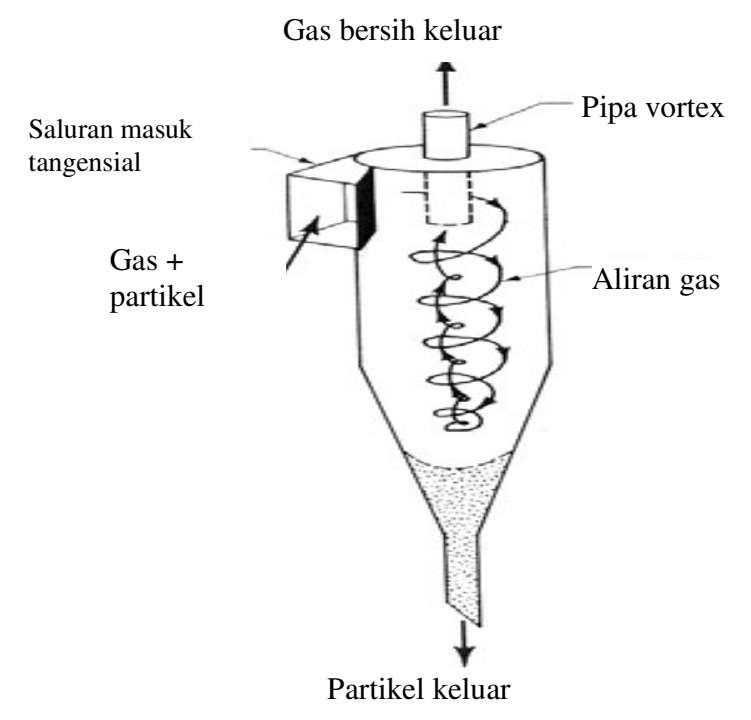

Gambar 1. Prinsip kerja siklon 
Akibatnya terjadi peningkatan pengumpulan partikel. Namun perlu diperhatikan bahwa perubahan diameter kerucut tidak mempengaruhi bentuk kurva efisiensi (Xiang et al., 2001).

Distribusi kecepatan tangensial tidak bervariasi secara signifikan terhadap arah aksial (Xiang and Lee, 2005). Perbedaan antara kecepatan tangensial dalam silinder bagian atas dan kerucut bagian bawah tidak terjadi. Hal ini menunjukkan bahwa tidak terjadi percepatan kecepatan dalam kerucut akibat penurunan luas penampang kerucut. Bagaimanapun, terjadi perbedaan kecepatan tangensial dalam siklon pada ketinggian yang berbeda. Kecepatan tangensial secara signifikan turun ketika ketinggian siklon meningkat dan ini bertanggung jawab pada rendahnya efisiensi pemisahan. Fenomena ini terjadi pada kerucut yang panjang. Satu perkecualian adalah bahwa jika siklonnya sangat pendek sehingga menyebabkan pipa gas keluar menonjol ke bagian kerucut sehingga efisiensi dari siklon akan turun akibat aliran pintas ke pipa gas keluar.

Menurut Kim dan Lee lapisan batas kecepatan yang terbentuk pada permukaan dinding siklon memegang peranan penting sebagai penghalang deposisi partikel karena terjadinya penurunan gaya sentrifugal yang tajam di daerah dekat dinding (Kim and Lee, 2001). Pemodelan turbulen perlu memperhitungkan difusi turbulen dalam daerah inti aliran dan gerakan partikel di dalam lapisan batas ini

\section{Model Turbulen}

Turbulen merupakan bentuk aliran yang berfluktuasi terhadap ruang dan waktu. Turbulen merupakan proses yang kompleks. Turbulen akan terjadi ketika gaya inersia dalam fluida menjadi sangat dominan dibandingkan gaya viskos (dicirikan dengan tingginya Reynolds, Re).

Implementasi turbulen dalam analisa numerik menghasilkan banyak sekali pendekatan. Terdapat 3 pendekatan utama dalam pemodelan turbulen sampai tahun terakhir, yaitu RANS (Reynolds Averaged Navier Stokes), LES (Large Eddy Simulation) dan DNS (Direct Numeric Simulation). Turunan dari model RANS adalah EVM (Eddy Viscosity Model) dan RSM (Reynolds Stress Models). EVM juga mempunyai turunan dari Zero Equation Model, Half Equation Model, One Equation Model, dan Two Equation Model. Two Equation Model mempunyai turunan $\mathrm{k}-\varepsilon$ model, $\mathrm{k}-\omega$ model, $\mathrm{k}-\tau$ model dan $\mathrm{v}^{2}-\mathrm{f}$ model. $\mathrm{k}-\varepsilon$ model mempuyai turunan $k-\varepsilon$ standar model, $R N G \quad k-\mathcal{E}$ model dan Realizable $k-\varepsilon$ model. Spalart-Allmaras model merupakan salah satu dari one equation model.

\section{Spalart-Allmaras Model}

Spalart-Allmaras model merupakan model turbulen yang sederhana karena tidak perlu menghitung skala panjang (length scale). Spalart-Allmaras efektif untuk memodelkan turbulen pada Re yang rendah. Karena kesederhanaannya, model Spalart-Allmaras perlu dicermati pada saat skala panjang dari aliran berubah secara tiba-tiba, misalnya persoalan aliran di sekitar lapisan batas dan di dekat dinding. Persamaan yang terlibat dalam model Spalart-Allmaras dapat dilihat dari Persamaan 1 sampai 9.

$$
\begin{aligned}
& \frac{\partial}{\partial t}(\rho \tilde{v})+\frac{\partial}{\partial x_{i}}\left(\rho \tilde{v} u_{i}\right)=\underbrace{C_{b 1} \rho \tilde{S} \tilde{v}}_{\text {production }} \\
& +\frac{1}{\sigma_{p}}\left[\frac{\partial}{\partial x_{j}}\left((\mu+\rho \tilde{v}) \frac{\partial \tilde{v}}{\partial x_{j}}\right)+C_{b 2} \rho\left(\frac{\partial \tilde{v}}{\partial x_{j}}\right)^{2}\right] \\
& -\underbrace{C_{w 1} \rho f_{w}\left(\frac{\tilde{v}}{d}\right)^{2}}_{\text {destruction }}+S_{v}
\end{aligned}
$$

dimana $\sigma_{\mathrm{p}}, \mathrm{C}_{\mathrm{b} 1}$ dan $\mathrm{C}_{\mathrm{b} 2}$ adalah konstanta. $v$ adalah viskositas kinematik molekular. $S v$ adalah sumber yang didefinisikan oleh pengguna. 
$\mu_{t}=\rho v f_{v 1}$

dimana $f_{v 1}$ adalah fungsi redaman viskos.

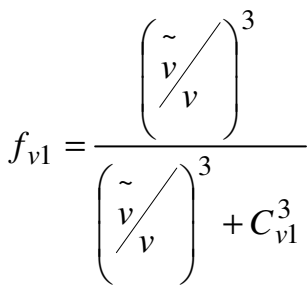

$\tilde{S} \equiv S+\frac{\tilde{v}}{\kappa^{2} d^{2}}\left(1-\frac{(\tilde{v} / v)}{1+(\tilde{v} / v) f_{v 1}}\right)$

dimana d adalah jarak dari dinding. S adalah ukuran skalar dari tensor deformasi.

$S \equiv \sqrt{2 \Omega_{i j} \Omega_{i j}}$

$\Omega_{i j}=\frac{1}{2}\left(\frac{\partial u_{i}}{\partial x_{j}}-\frac{\partial u_{j}}{\partial x_{i}}\right)$

$f_{w}=g\left[\frac{1+C_{w 3}^{6}}{g^{6}+C_{w 3}^{6}}\right]^{1 / 6}$

$g=\frac{\tilde{v}}{\tilde{S} \kappa^{2} d^{2}}+C_{w 2}\left\{\left(\frac{\tilde{v}}{\tilde{S} \kappa^{2} d^{2}}\right)^{6}-\left(\frac{\tilde{v}}{\tilde{S} \kappa^{2} d^{2}}\right)\right\}$

Konstanta yang digunakan dalam persamaan model Spalart dan Allmaras adalah:

$$
\begin{aligned}
& C_{b 1}=0,1355, C_{b 2}=0,622, \sigma_{p}=\frac{2}{3}, \\
& C_{v 1}=7,1 C_{w 1}=\frac{C_{b 1}}{\kappa^{2}}+\frac{\left(1+C_{b 2}\right)}{\sigma_{p}},
\end{aligned}
$$

$C_{w 2}=0,3, C_{w 3}=2,0, \quad \kappa=0,4187$

\section{RNG k- $\varepsilon$ model}

Berbeda dengan model SpalartAllmaras, model RNG (Renormalized Group) k- $\varepsilon$ merupakan model dua persamaan dimana energi kinetik turbulen (k) dan laju disipasi ( $(\varepsilon)$ dimodelkan. Viskositas Eddy dihitung dari hubungan $\mathrm{k}$ dan $\varepsilon$. Model RNG k- $\varepsilon$ mempunyai respon yang lebih baik terhadap pengaruh regangan dan sudut garis arus yang cepat dibanding model k- $\varepsilon$ standar. Persamaan yang berlaku dalam model RNG k- $\varepsilon$ dapat dilihat pada Persamaan 10 sampai 13.

Persamaan k:

$$
\begin{aligned}
& \frac{\partial}{\partial t}(\rho k)+\frac{\partial}{\partial x_{i}}\left(\rho k u_{i}\right)=\frac{\partial}{\partial x_{j}}\left(\alpha_{k} \mu_{\text {eff }} \frac{\partial k}{\partial x_{j}}\right) \\
& -\underbrace{\rho \overline{u_{i} u_{j}} \frac{\partial u_{j}}{\partial x_{i}}}_{\text {Production }}-\underbrace{g_{i} \frac{\mu_{t}}{\rho \operatorname{Pr}_{t}} \frac{\partial \rho}{\partial x_{i}}}_{\text {Bouyancy }}-\rho \varepsilon \\
& -\underbrace{2 \rho \varepsilon M_{t}^{2}}_{\text {compressibility }}+S_{k}
\end{aligned}
$$

Persamaan $\varepsilon$ :

$$
\begin{aligned}
& \frac{\partial}{\partial t}(\rho \varepsilon)+\frac{\partial}{\partial x_{i}}\left(\rho \varepsilon u_{i}\right)=\frac{\partial}{\partial x_{j}}\left(\alpha_{\varepsilon} \mu_{e f f} \frac{\partial \varepsilon}{\partial x_{j}}\right) \\
& +C_{1 \varepsilon} \frac{\varepsilon}{k}\left(\rho \overline{u_{i} u_{j}} \frac{\partial u_{j}}{\partial x_{i}}+C_{3 \varepsilon} g_{i} \frac{\mu_{t}}{\rho \operatorname{Pr}_{t}} \frac{\partial \rho}{\partial x_{i}}\right) \\
& -C_{2 \varepsilon} \rho \frac{\varepsilon^{2}}{k}-\frac{C_{\mu} \rho \eta^{3}\left(1-\eta / \eta_{0}\right)}{1+\beta \eta^{3}} \frac{\varepsilon^{2}}{k}+S_{\varepsilon}
\end{aligned}
$$

viskositas turbulen dinyatakan dengan:

$\mu_{t}=\rho C_{\mu} \frac{k^{2}}{\varepsilon}$

Beberapa konstanta yang dipakai dalam RNG k- $\varepsilon$ adalah:

$$
\begin{aligned}
& C_{\mu}=0,0845, \eta \equiv S k / \varepsilon, \eta_{0}=4,38, \\
& \beta=0,012, C_{1 \varepsilon}=1,42, C_{2 \varepsilon}=1,68, . . \\
& \quad \alpha_{k}=\alpha_{\varepsilon}=1,393
\end{aligned}
$$

\section{METODE PENELITIAN}

Unjuk kerja dan karakteristik aliran siklon akan dianalisis dengan menggunakan metode numerik dengan bantuan perangkat lunak FLUENT. Analisa numerik dilakukan dengan menggunakan metode finite volume. Persamaan kontinuitas dan persamaan Navier Stokes akan dipecahkan secara tahap demi tahap (segregated). Interaksi partikel dengan gas akan dipecahkan dengan menggunakan metode EulerLagrangian. 
Tabel 1. Analisis ayak partikel yang masuk siklon (Funk, P.A, et al., 2000).

\begin{tabular}{ccc}
\hline Sieve & Ukuran $(\mu \mathrm{m})$ & Fraksi Massa $(\%)$ \\
\hline 12 & $>1679$ & 1,3 \\
100 & $>149$ & 56,4 \\
140 & $>106$ & 5,5 \\
200 & $>75$ & 5,2 \\
270 & $>53$ & 6,4 \\
400 & $>37$ & 5,7 \\
& $<37$ & 19,4 \\
\hline
\end{tabular}

Analisis ayak dari partikel dapat dilihat pada Tabel 1. Gambar siklon dan mesh yang digunakan untuk memisahkan debu dan udara seperti dapat dilihat gambar 2.

\section{HASIL DAN PEMBAHASAN}

Dari hasil simulasi CFD diperoleh bahwa waktu tinggal partikel di dalam siklon berkisar antar 0,36 sampai 0,44 s. Partikel akan bergerak kebawah dalam bentuk menyerupai spiral (lihat Gambar 3 kiri). Pada pemodelan ini, ketika partikel membentur dinding, maka diasumsikan akan terpental (tidak terjadi slip).

Dari vektor kecepatan (Gambar 3 tengah) dan kontour kecepatan (Gambar 3 kanan) terlihat bahwa terjadi aliran pintas gas ke pipa keluar. Aliran pintas terjadi sampai hampir diketinggian setengah dari bagian kerucut. Setengah bagian kerucut ke bawah, gas akan mengalami percepatan karena perubahan luas penampang dari kerucut.

Gambar 4 dan Gambar 5 memperlihatkan profil kecepatan gas dari model turbulen Spalart-Allmaras dan model RNG k- $\varepsilon$. Dari kedua model turbulen terlihat bahwa dengan semakin besar kecepatan masuk menyebabkan aliran pintas gas ke pipa keluar semakin rendah. Hal ini diperjelas dengan semakin tingginya bagian gas yang mengalami peningkatan kecepatan di bagian bawah kerucut.

Pengaruh kecepatan udara masuk pada efisiensi dan penurunan tekanan dapat dilihat pada Gambar 6 dan Gambar 7. Dari Gambar 6 terlihat bahwa semakin besar kecepatan gas masuk ke siklon, maka terjadi peningkatan penurunan tekanan.

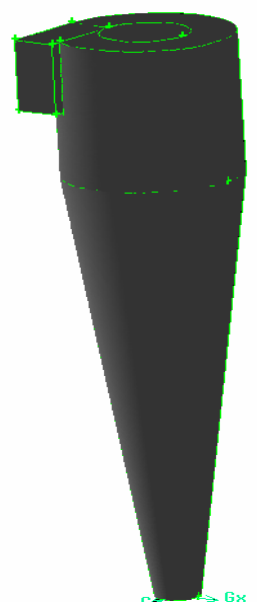

Gambar 2. Siklon yang digunakan dalam penelitian 
Dengan mengubah kecepatan aliran masuk dari $13,2 \mathrm{~m} / \mathrm{s}$ menjadi $17,8 \mathrm{~m} / \mathrm{s}$ akan meningkatkan penurunan tekanan hampir dua kali lipat. Penurunan tekanan yang terlalu besar tentu tidak dikehendaki karena diperlukan biaya operasi yang mahal. Biaya operasi yang besar ini dikarenakan diperlukannya kompresor yang mempunyai daya yang lebih besar tersebut.
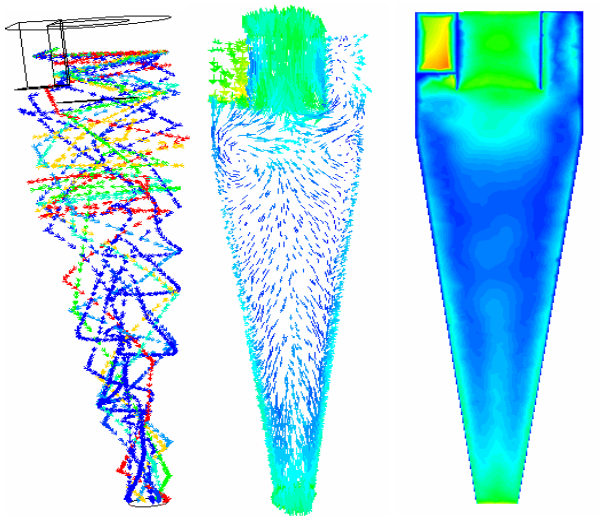

Gambar 3. Profil aliran salah satu partikel (kiri) dan profil vektor kecepatan gas (tengah) dan kontour kecepatan gas (kanan) di dalam siklon
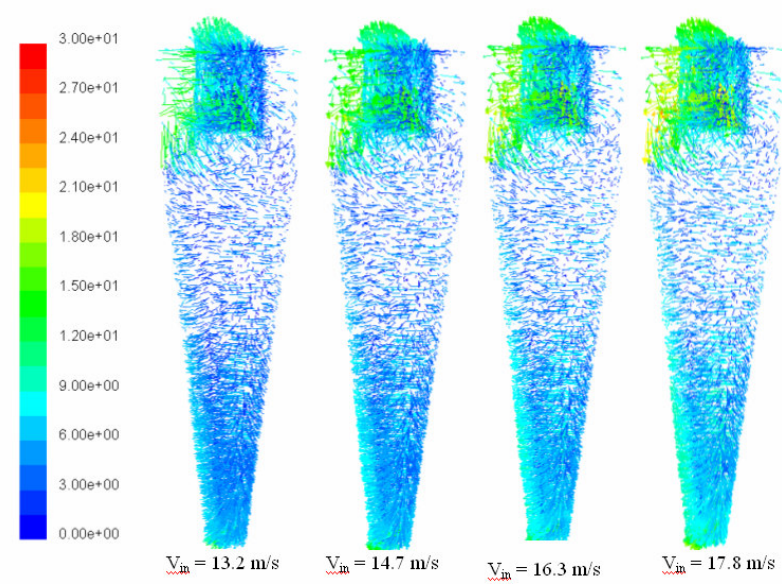

Gambar 4. Profil kecepatan model Spalart-Allmaras untuk berbagai kecepatan masuk.
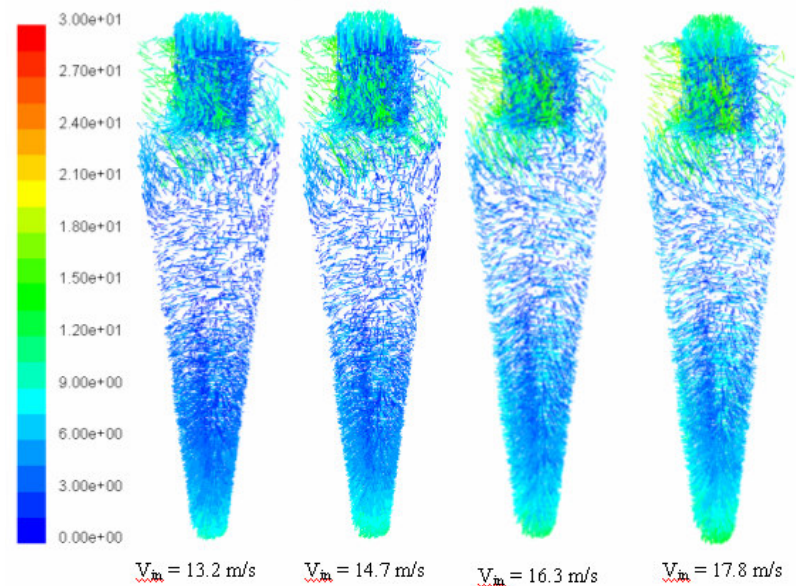

Gambar 5. Profil kecepatan model RNG k- $\varepsilon$ untuk berbagai kecepatan masuk 
Model Spalart-Allmaras memberikan prediksi penurunan tekanan yang lebih baik dibandingkan model turbulen RNG k- $\varepsilon$. Model Spalart-Allmaras juga lebih sensitif terhadap perubahan kecepatan dibandingkan model RNG k- $\varepsilon$ (perhatikan Gambar 4 dan Gambar 5).

Efisiensi pemisahan partikel dari gas untuk berbagai kecepatan gas masuk siklon dapat dilihat pada Gambar 7. Dari eksperimen (Funk, P.A. et al., 2000) terlihat bahwa dengan mengubah kecepatan gas masuk dari 13,2 m/s menjadi $17,8 \mathrm{~m} / \mathrm{s}$ tidak terjadi pengaruh yang signifikan pada efisiensi. Model turbulen Spalart-Allmaras memberikan prediksi efisiensi pemisahan partikel lebih baik dibandingkan model RNG k- $\varepsilon$.
Secara umum dapat dilihat bahwa model Spalart-Allmaras, walaupun hanya model satu persamaan ternyata mampu memberikan prediksi lebih baik terhadap penurunan tekanan dan efisiensi pada siklon dibandingkan model dua persamaan RNG k- $\varepsilon$. Hal ini dapat dijelaskan karena dalam siklon ini dengan kecepatan gas masuk $13,2 \mathrm{~m} / \mathrm{s}$ sampai $17,8 \mathrm{~m} / \mathrm{s}$ hanya menghasilkan Re maksimum 3100. Ini menunjukkan bahwa kalaupun terjadi turbulen di dalam siklon, maka turbulen yang terjadi adalah turbulen pada bilangan Re yang rendah. Sesuai dengan karakteristiknya model turbulen SpalartAllmaras lebih sesuai digunakan pada kondisi seperti ini dibandingkan model k- $\varepsilon$.

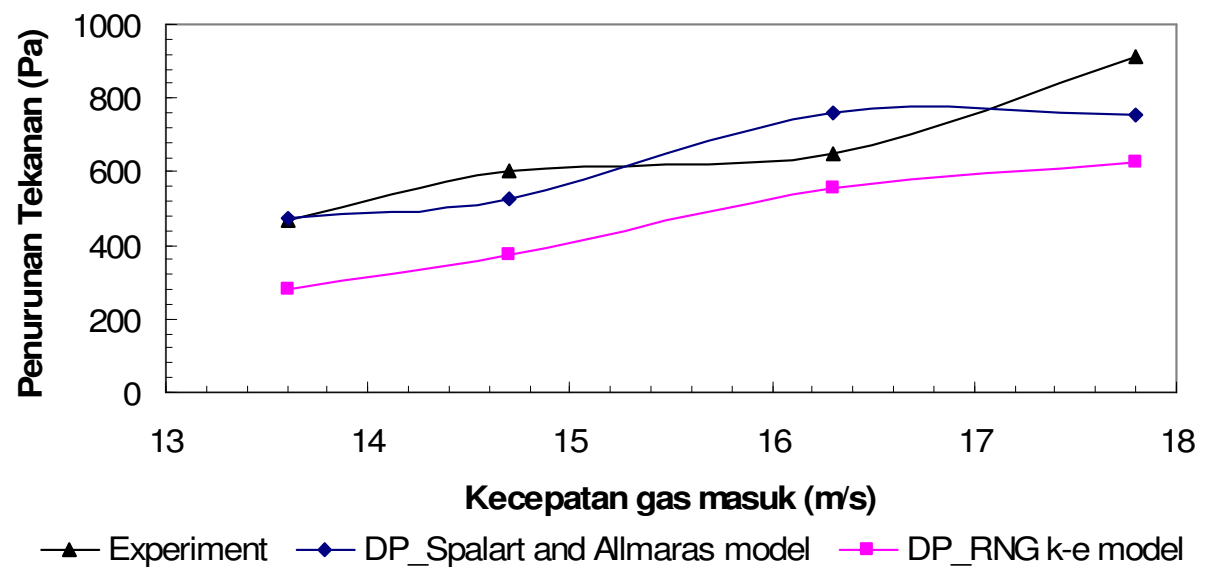

Gambar 6. Pengaruh kecepatan gas masuk terhadap penurunan tekanan

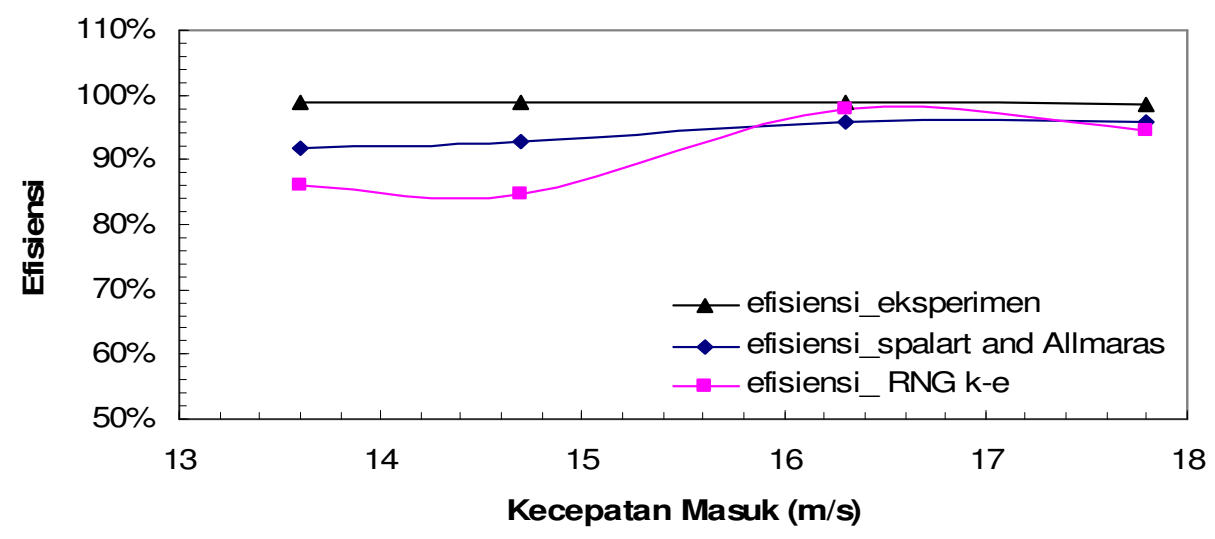

Gambar 7. Perubahan efisiensi akibat kecepatan gas masuk 


\section{KESIMPULAN}

Dari penelitian ini dapat disimpulkan beberapa hal:

1. Desain siklon pada penelitian ini masih memungkinkan terjadinya aliran pintas sehingga perlu dilakukan modifikasi misalnya mengubah sudut aliran masuk atau mengubah panjang pipa keluar.

2. Siklon ini mampu menghasilkan efisiensi pemisahan partikel di atas $90 \%$ dan tidak tergantung pada kecepatan aliran masuk.

3. Dengan meningkatnya kecepatan aliran masuk dari $13,2 \mathrm{~m} / \mathrm{s}$ menjadi $17,8 \mathrm{~m} / \mathrm{s}$ akan meningkatkan penurunan tekanan hampir dua kali lipat.

4. Meningkatnya aliran masuk akan menyebabkan aliran pintas gas ke pipa keluar juga berkurang sehingga efisiensi pemisahan partikel meningkat sedikit.
5. Model Spalart-Allmaras lebih baik dalam memprediksi penurunan tekanan dan efisiensi pemisahan partikel dalam siklon untuk kisaran kecepatan gas masuk $13,2 \mathrm{~m} / \mathrm{s}$ sampai $17,8 \mathrm{~m} / \mathrm{s}$ dibandingkan model turbulen RNG k- $\varepsilon$.

Selanjutnya penelitian dapat dilanjutkan dengan melakukan modifikasi geometri dan ukuran siklon untuk memperoleh penurunan tekanan yang rendah. Penelitian terhadap berbagai model turbulen yang lain juga dapat terus dilanjutkan.

\section{PERSANTUNAN}

Penulis mengucapkan terima kasih kepada seluruh staf dan karyawan Intitute of Thermal Engineering, TU Graz Austria sehingga pemodelan siklon dengan bantuan CFD-FLUENT dapat terlaksana.

\section{DAFTAR PUSTAKA}

Bernardo, S., Peres, A.P, Mori, M., 2005, Computational Study of Ciclone Flow Fluid Dynamics Using a Different inlet section angle, Thermal Engineering, Vol. 4 No. 1. June 2005, p. 18-23.

Cooper, C.D. and Alley, F.C, 1986, Air Pollution Control, USA.

Funk, P.A., Ed Hughs, S. , Holt, G.A., 2000, Entrance Velocity Optimization for Modified Dust Cyclones, The Journal of Cotton Science 4: 178-182 (2000).

Kim, C.H. and Lee, J.W., 2001, A New Collection Efficiency Model for Small Cyclones Considering the Boundary-Layer Effect, Aerosol Science 32 (2001) p. 251-269

Mukherjee, A.K., Sripriya, R., Rao, P.T., Das, P., 2003, Effect of Increase in Feed Inlet Pressure on Feed Rate of Dense Media Cyclone, Int.J.Miner.Process.69(2003) p.259- 274.

Peng. W., Hoffmann, A.C., Dries, H.W.A., Regelink, M.A., and Stein, L.E, 2005, Experimental Study of the Vortex End in Centrifugal Separators: The Nature of the Vortex End, Chemical Engineering Science 60 (2005) p.6919 - 6928.

Xiang, R., Park, S.H, and Lee, K.W., 2001, Effects of Cone Dimension on Cyclone Performance, Aerosol Science 32 (2001) p.549-561.

Xiang, R.B. and Lee, K.W., 2005, Numerical Study of Flow Field in Cyclones of Different Height, Chemical Engineering and Processing 44 (2005) p. 877-883 